\title{
A Study of Perceived Nature, Shade and Trees and Self-Reported Physical Activity in Denver
}

\author{
Sara Tabatabaie, Jill S. Litt * and Amanda Carrico \\ Environmental Studies Program, University of Colorado Boulder, Boulder, CO 80309, USA; \\ sara.tabatabaie@colorado.edu (S.T.); Amanda.Carrico@colorado.edu (A.C.) \\ * Correspondence: jill.litt@colorado.edu or jill.litt@isglobal.org
}

Received: 19 August 2019; Accepted: 20 September 2019; Published: 26 September 2019

\begin{abstract}
Background: Current evidence on the association between greenery and physical activity (PA) remains inconsistent. Most studies on this association use objective measures of greenness, which do not reveal people's perceptions of greenness in neighborhoods, or the role of quality components of greenness, such as shade, trees, and the presence of nature on this association. (2) Methods: Drawing on data from the Neighborhood Environment and Health Survey-a cross-sectional population-based survey of Denver residents in 2007-we examined which measures of greenness (perceived and objective) correlated with the self-reported PA. We also assessed how components of perceived greenness, shade, trees and the presence of nature, correlated with PA. (3) Results: Perceived greenness, reflecting perception of trees, shade and the presence of nature, was positively associated with reported moderate-vigorous PA. Conclusion: Findings provide evidence that quality aspects of greenness affect people's perception of the neighborhood in a way that relates to PA. The individual contributions of shade, trees, and the presence of nature in this association should be analyzed in future studies. Understanding the link between shade and trees and PA has implications for how to plan for walkability and sun safety at the neighborhood scale.
\end{abstract}

Keywords: physical activity; perceived greenness; shade; trees; objective greenness

\section{Introduction}

Integrating physical activity (PA) into daily routines has become a national priority following the American College of Sports Medicine/Centers for Disease Control's statement on PA and health [1] and the U.S. Surgeon General's Report on Physical Activity and Health [2]. The 21st-century active-living agenda is concerned with the negative health impacts of physical inactivity and poor diet [3]. This agenda calls for strategies that target multiple levels of influence (individual, inter-personal, organizational, community and policy) to promote PA. Moderate-intensity activities, such as walking, are deemed an important way to achieve daily PA goals. Neighborhood-based strategies offer opportunities to make moderate-intensity activities such as walking and biking a possibility for people living in all kinds of neighborhoods and across all kinds of social groups.

Neighborhood design can have direct and indirect effects on PA and people's perception of the desirability of the neighborhood for PA, respectively [4-6]. Active-living research priorities include understanding streetscape features within the neighborhood context and their role in shaping PA levels. As a component of neighborhood environments, urban greenness-urban parks, and street greenery in particular-seems to advance PA [7-14]; however, evidence on the link between urban greenness and PA remains inconsistent due to measurement variations, definitions, context and cultural differences, and small sample sizes [15-21]. 
1.1. Conceptualizing Perceived Greenness through Components of Landscape Quality: Trees, Natural Features, and Shade

Neighborhood greenness has been shown to foster positive perceptions of the neighborhood environment and, therefore, influences a variety of pro-health behaviors and improved health status [7-14]. The "quality" of landscapes and vegetation is a facet through which people experience the place, perceive the desirability of the area and interact with the surrounding environment. Gobster (2007) posits that a human's response to the environment is affected by his/her experience of the surrounding landscape. He defines the "perceptible realm" as the scale at which humans perceive the environment. We perceive the surrounding landscape through all our senses. He suggests that people tend to interact with or protect landscapes that are perceived as more aesthetically pleasing [22]. Moreover, studies suggest the quality of landscape is a facet through which the surrounding environment may affect health behavior [23,24].

The quality of greenness is closely related to perceived neighborhood aesthetics, which has been parameterized in different public health and planning studies. For example, Pikora et al. (2003) assesses streetscape aesthetics using eight items: cleanliness, sights, garden maintenance, parks, pollution, trees, architecture, and street maintenance [25]. For Ball et al. (2001), neighborhood aesthetics are defined by the level of friendliness of the neighborhood, the attractiveness of the local area, and the invitingness of the neighborhood for walking [26]. Handy et al. (2002) measured neighborhood aesthetics based on the percent of ground in shade at noon, and the lack of incivilities (number of locations with graffiti per square mile) [27]. For Sugiyama et al. (2010), the aesthetic factors that made areas more conducive to recreational walking include the suitability of the area for chatting and children's play, the welcoming and relaxing quality of the area, and the quality of trees and plants [28]. Saelens and others (2003) assessed neighborhood aesthetics according to the existence of trees and natural sights, adequate shade, attractive landscaping, and attractive buildings in the neighborhood [23,29]. Most of these studies have shown a positive relationship between the aesthetic quality of streetscapes and PA $[8,25,26,30]$.

The presence of trees and natural features are common neighborhood characteristics that represent the quality of greenness and have been linked with PA behavior [16,17,31-33]. Shade is another facet of the quality of the natural environment but has mostly been studied within the parks and educational settings [34-39]. However, shade should be included in studies of nearby nature and PA, given that outdoor-based PA may carry some risks due to extreme heat, thermal discomfort [40], and harmful levels of UV exposure from the sun. Shade is viewed as a precious commodity to reduce the hazards of excessive UV exposure and rising temperatures and is created naturally by tree canopies or artificially through shade structures. It also contributes to the aesthetic quality of streetscapes and can affect people's PA behavior $[25,41-43]$.

\subsection{Measuring Quantity of Greenness through Objective Assessments of the Environment}

Neighborhood greenness has been measured differently in studies that link PA to greenness. The three main ways greenness is assessed include perceived measures of greenness using surveys, observed measures of greenness using valid and reliable audit tools, and objective measures of greenness derived from GIS and satellite imagery. According to Leslie (2010), a majority of studies that show significant relationships between greenness and PA are those that collect perceived greenness measures (e.g., perception of trees, shade, and the presence of nature). In contrast, studies that use objective measures, such as Normalized Difference Vegetation Index (NDVI) or GIS-driven measures, report less significant or no association between greenness and PA levels [28]. Sarkar attributes the inconsistency in the association between greenery and PA to differences in definitions of green space, and different methods applied to parameterize greenery [16].

\subsection{Measuring Quality of Greenness through Perceived Assessments of the Environment}

While objective measures of greenness reflect the quantity of greenery or access to green space, perceived measures reveal how people perceive the presence or quality of greenness. Some studies 
suggest that the size and distance to green space do not predict the effective use of the green space, but there are other factors that may affect the use of urban greenness [44]. Also, in some instances, a large green space in urban areas may increase distances between other amenities and destinations resulting in less walking or cycling [45].

\subsection{Factors Mediating People's Perception of the Environment}

People's perception of the surrounding environment and the way this perception affects health behaviors, PA behavior in particular, may be influenced by their attitudes and socio-economic characteristics, such as age, ethnicity, and level of income and education [46,47]. People's perception of safety has been shown to affect PA behavior in many studies [48-51]. The time of the year may also affect this perception. Some studies also show that the level of the walkability of the neighborhood may affect its residences' perception of the surrounding areas [52]. Moreover, the length of residency in the neighborhood is important because it can influence people's relationships to the neighborhood environment and related perceptions of this place $[53,54]$. These factors are considered important mediators of the association between greenness and PA.

\subsection{Exploring Associations between the Quantity and Quality of Greenness and PA Behavior}

Although there is evidence suggestive of a link between neighborhood greenness and PA behavior, there are still discussions over the importance of the quantity versus the quality of greenness in this association. In this study, we aim to assess the following: (1) which measures of greenness-perceived and/or objective-are correlated with reported PA at the block group level, one type of proxy for neighborhoods; (2) whether and how this association differs for moderate-vigorous, and light levels of PA; (3) how the quality of perceived greenness, including available shade, trees, and the presence of nature, correlates with PA. We draw on data from the Neighborhood Environment and Health Survey, a population-based survey [55], to explore the relationships between perceived and objective greenness and reported PA. Specifically, we hypothesize that PA is more significantly correlated with perceived greenness, as measured by perceptions of the presence of trees, shade, and nearby nature than the quantity of greenness as measured by NDVI. We also hypothesize that positive perceptions of greenness influence all types of PA behavior, including light, moderate and vigorous levels of PA.

\section{Materials and Methods}

Data for this study were collected using a population-based survey and neighborhood audits across 92 block groups in Denver, Colorado. (Census block groups are geographic units, between census blocks and census tracts that contain between 600 to 3000 people. Block groups are used by the United States Census Bureau to present census data.) The survey was conducted from 2006 to 2007. Block groups were located east of a major interstate highway (I-25). A total of 474 residents participated in a 45-minute face-to-face survey. The participants were initially selected using a multi-frame sampling design. This sampling consisted of an area-based sample of the general population and a list-based census of community gardeners with a recruitment goal of 480 households from 40 block groups. A total of 1151 households were randomly selected within the area-based sample. Of the initial 1451 selected households, 648 could not be contacted. Of the 803 contacted households, 474 (response rate $=59 \%$ ) participated in the survey [56]. One eligible respondent aged 18 or over was randomly selected from each household using the "most recent birthday" method. The sample size was initially determined to satisfy the statistical power of 0.8 . The sample size was increased by $45 \%$ to account for possible non-respondents. We limited our sample to block groups that included at least two households $(n=58)$ to keep the level of accuracy of the regression coefficients and variances $[57,58]$. The average sample size was 7.5 participants per block group. More details about sampling and study design can be found in the following sources $[14,55,56]$.

The survey questionnaire was developed based on existing surveys on neighborhood and health and included items on aesthetics [29], social involvement [59], neighborhood attachment [60], 
physical activity, and dimensions of health $[14,55,56]$. Questions were available in English and Spanish. Data were collected through a 45-minute face-to-face survey at or near the home of the respondent.

In support of this analysis, we developed one objective measure of the neighborhood greenness: the Normalized Difference Vegetation Index (NDVI) for each block group. NDVI for each block group was created using Environment for Visualizing Images (ENVI) software. Landsat images acquired from USGS Earth Explorer were used to develop NDVI, which is an index of photosynthetic activity or plant greenness. NDVI shows the density of green on a patch of land by calculating the normalized difference between the red and near-infrared bands from an image. A larger NDVI value corresponds to denser vegetation.

$$
\mathrm{NDVI}=\frac{(\mathrm{NIR}-\mathrm{RED})}{(\mathrm{NIR}+\mathrm{RED})}
$$

The reason that we selected NDVI as the objective greenness variables was because most studies evaluating the association between objective greenness and PA have used NDVI as the measure of greenness. Using this measure allows us to compare our results with similar studies. NDVI was attached to the dataset via the block group ID.

Dependent measure: Self-reported physical activity

We used the Community Healthy Activities Model Program for Seniors (CHAMPS) Physical Activity Questionnaire to assess PA behavior. This instrument captures the weekly frequency and intensity of undertaken activities, such as swimming, tennis, golf, dance, walking for the purpose of leisure or exercise, and light and heavy gardening. Outcome measures denoted the weekly frequency and duration of PA undertaken by adults at light (e.g., leisurely walking, light gardening), moderate-vigorous (e.g., cycling, heavy housework, tennis and jogging) and total hours of PA/week [61]. We generated two measures of PA, moderate-vigorous, and light, by combining the reported hours of PA items according their metabolic equivalent value (MET value). The moderate-vigorous category includes physical activities of MET $\geq 3$ [61,62].

Composite variable: Perceived green

Participants' perceptions of trees, shade and the presence of nature in the neighborhood were measured in the survey. Respondents rated these features on a scale from 1 (Strongly Disagree) to 4 (Strongly Agree). These three variables showed high correlations ( $\mathrm{r}>0.4$ ); we performed an Exploratory Factor Analysis (EFA) to account for high correlations between these variables and explore the latent variables. The factor analysis resulted in one factor, namely perceived green. This composite variable evaluates people's perceptions of trees, shade and the presence of nature while they are walking in the neighborhood $(\alpha=0.76)$ (Table 1$)$.

Table 1. Factor loadings and squared multiple correlations of the variables with Perceived Green.

\begin{tabular}{cc}
\hline Squared multiple correlations of the variables with the factor & 0.73 \\
\hline \multicolumn{3}{c}{ Factor Loadings } \\
\hline Perception of the presence of trees in neighborhood & 0.78 \\
Perception of the presence of shade in neighborhood & 0.74 \\
Perception of access to nature in neighborhood & 0.57 \\
\hline
\end{tabular}

\section{Composite variable: Perceived safety}

Participants' perceptions of being attacked or robbed, and overall crime in the neighborhood were measured in the survey. Perceived safety is a composite variable, assessing people's fear of crime and their idea about safety in their neighborhood $(\alpha=0.85)$ Table 2. 
Table 2. The composite green measure and composite safety measure used in analysis.

\begin{tabular}{|c|c|c|}
\hline Composite Measure & Scale & Cronbach's Alpha \\
\hline $\begin{array}{l}\text { Perceived Green } \\
\text { There are trees along the streets in my neighborhood. } \\
\text { Trees give shade for the sidewalks in my neighborhood. } \\
\text { There are many attractive natural sights in my neighborhood } \\
\text { (such as landscaping, views). }\end{array}$ & $\begin{array}{l}\text { 4-point scale: strongly agree to } \\
\text { strongly disagree }\end{array}$ & 0.76 \\
\hline $\begin{array}{l}\text { Perceived Safety [45] } \\
\text { How afraid are you of being attacked or robbed: } \\
\text { - At home in your house or apartment? } \\
\text { - On the streets of your neighborhood during the day? } \\
\text { - Out alone at night in your neighborhood? }\end{array}$ & $\begin{array}{l}\text { 4-point scale (very fearful to not } \\
\text { fearful) }\end{array}$ & 0.85 \\
\hline $\begin{array}{l}\text { Has fear of crime in your neighborhood caused you to limit } \\
\text { the places or times that you will: } \\
\text { - Go shopping? } \\
\text { - Work? } \\
\text { - Go by yourself? }\end{array}$ & Yes/no & \\
\hline
\end{tabular}

\section{Objective Greenness}

As described above, we used NDVI as the objective measures of greenness.

\section{Control Variables}

We included self-reported age category, gender, level of education $(1=$ not high school graduate; 2 = high school graduate or some college; 3 = college grad), the presence of children under 18 in the household (yes/no), and ethnicity dummy variables (White, African American, and Hispanic) as socio-demographic control variables [46]. Self-reported health was included as a proxy for health status. This item was assessed using a single item from the Behavioral Risk Factor Surveillance System Survey (BRFSS), showing how respondents rate their general health on a scale of 1 (poor) to 5 (excellent). It has been shown to be a valid and reliable measure of health status [63].

\section{Walkability Index}

We used the GIS-derived macro-level walkability index (WI) to classify our block groups into low and high walkable areas. The walkability index was derived as a function of net residential density, intersection density, retail floor area ratio, and land use mix [64,65]. We applied GIS to develop the WI. Data were retrieved from the City of Denver Open Data Catalog. The mean WI was used as the break point between low and high walkable areas.

\section{Seasonal effect}

Through our analysis, we found an association between the month of the interviews and reported PA levels. The maximum level of PA was reported in June and July. Reported hours of PA showed a linear decrease before and after these two months. We recoded the month of interview to reflect this pattern and used this variable in our models to adjust for seasonal effects. In the new scheme, we defined two intervals for the first and second halves of the year. In the first interval, our variable increased from Jan $=1$ to June $=6$; in the second interval, our variable decreased from July $=6$ to Dec $=1$.

\section{Length of residency}

The length of residency variable represented the number of years respondents lived in the neighborhood $(1=1-2$ yrs; $2=2-7$ yrs; $3=8-17$ yrs; $4=>17$ yrs $)$. 


\section{Data analysis}

We applied multilevel statistical models to examine the association between two levels of PA and greenness measures, while accounting for the differences in PA across block groups. We calculated the statistical models of respondents nested in block groups via PROC MIXED in SAS version 4.9. This software is manufactured by SAS Institute Inc. based in Cary, North Carolina, USA.

We applied the random intercept model to develop the block group models. The multicollinearity between variables was checked using variance inflation factors (VIF). We did not find significant problems with multicollinearities (VIFs < 2.5). We started with intercept-only models to understand the variation of PA across the block groups. We then developed our preliminary multivariable models by adding the control variables_age, educational attainment, gender, ethnicity, self-reported health, the presence of children under 18 in the household, the length of residency in the neighborhood, and the month of the interview-one at a time to the intercept model (data not shown). Of these variables, ethnicity, the presence of children under 18, and the length of residency were excluded from models in the multivariable analysis because they showed non-significant regression coefficients in the univariate analysis.

Greenness variables were added to the preliminary models one at a time. Models with the lowest -2loglikelihood were selected as the best models (Models A-B). The perceived safety variable, as well, was excluded from multivariable models because it showed a non-significant regression coefficient in the univariate analysis.

We also checked whether the level of walkability affected the association between PA and the green variables by adding the walkability index to the models (Models C-D). Prior to this step, we checked the significance of interaction terms (WI x perceived green), (WI x self-reported health), and (WI x NDVI) using PROC GLM. Interaction terms were excluded from models since their coefficients were not significant. Table 4 lists final models, including only statistically significant variables.

\section{Results}

Table 3 summarizes the characteristics of the respondents in our analysis and shows hours of PA by demographic and socioeconomic characteristics. Five records were dropped because of missing values $(\mathrm{N}=469)$.

Participants were mostly women (67.4\%), White (57.8\%), and obtained a college degree or higher (57.4\%). The average age of participants was 46 years. Most respondents reported good, very good, or excellent health (80.3\%). On average, respondents did $7.8 \mathrm{~h}$ of light PA/week and $10.7 \mathrm{~h}$ of moderate-vigorous PA/week.

The reported hours of moderate-vigorous PA were statistically higher among males, Whites, and respondents with at least a college degree. The hours of moderate-vigorous PA were also higher among respondents who reported a better health condition. The hours of light activity were higher among respondents between 65 and 95 years old, as well as among participants who reported a poor health condition.

Table 4 presents the estimated univariate parameters $(\beta)$ and results from multi-level models (A-D). The reported hours of PA at moderate-vigorous level was positively associated with people's perception of greenness in their neighborhoods, after adjustment for educational attainment, age, gender, health, and the month of the interview. This association was not significant for PA at light level (Models A and B).

This result implies that components of perceived greenness, participants' perception of shade, trees, and the presence of nature positively affect levels of PA at moderate-vigorous level. However, a high correlation between the components of the perceived green variables - shade, trees, and the presence of nature-does not allow us to tease out the exact contribution of each of these items in the association between PA variables and the perceived green variable (Table 5). 
Table 3. Number (\%) distribution of characteristics of survey respondents by demographic, health, greenness measures and physical activity $(\mathrm{PA})$ variables $(\mathrm{N}=469)$.

\begin{tabular}{cccc}
\hline Demographic and Health Variables & $\begin{array}{c}\text { Characteristics of } \\
\text { Respondents } \\
\text { Number (\%) }\end{array}$ & $\begin{array}{c}\text { Hours of Moderate-Vigorous } \\
\text { PA/Week } \\
\text { Mean (95\% of CI) }\end{array}$ & $\begin{array}{c}\text { Hours of Light PA/Week } \\
\text { Mean (95\% of CI) }\end{array}$ \\
\hline $\begin{array}{c}\text { Demographic and socio-economic } \\
\text { characteristics } \\
\text { Gender }\end{array}$ & & & \\
Male (1) & $153(32.6)$ & $12.2(10.6,13.8)$ & $8.1(7.2,9.1)$ \\
Female (2) & $316(67.4)$ & $10.0(9.1,10.9)$ & $7.6(7.1,8.2)$ \\
Ethnicity & & & \\
White (1) & $271(57.8)$ & $11.1(10.1,12.1)$ & $7.6(7.0,8.2)$ \\
Non-White (0) & $198(42.2)$ & $10.2(8.9 .11 .5)$ & $8.1(7.3,8.9)$ \\
Education & $52(11.1)$ & $5.8(3.9,7.7)$ & \\
Less than high school (1) & $148(31.6)$ & $10.3(8.9,11.7)$ & $8.8(5.4,8.2)$ \\
High school or some college (2) & $269(57.4)$ & $11.7(10.6,12.8)$ & $7.9(7.2,9.0)$ \\
College graduate or higher (3) & & & \\
Age category & $30(6.4)$ & $10.0(7.4,12.6)$ & $6.7(4.7,8.7)$ \\
18-24 (1) & $195(41.8)$ & $11.2(10.1,12.4)$ & $7.1(6.5,7.7)$ \\
25-44 (2) & $177(37.9)$ & $11.5(10.0,13.0)$ & $7.7(6.9,8.5)$ \\
45-64 (3) & $65(13.9)$ & $7.2(5.7,8.7)$ & $10.8(9.1,12.4)$ \\
65-94 (4) & & & \\
Yes (1) & $158(34.5)$ & $10.6(9.2,11.9)$ & $8.3(7.5,9.1)$ \\
No (2) & $300(65.5)$ & $11.0(9.9,12.0)$ & $7.7(7.1,8.3)$ \\
Children & & \\
Poor & $14(3)$ & $8.9(4.7,13.1)$ & $9.9(5.5,14.3)$ \\
Fair & $78(16.7)$ & $8.4(6.5,10.3)$ & $8.0(6.8,9.2)$ \\
Good & $119(25.5)$ & $9.2(7.8,10.5)$ & $7.1(6.3,8.0)$ \\
Very good & $156(33.4)$ & $10.7(9.4,12.0)$ & $7.9(7.1,8.8)$ \\
Excellent & $100(21.4)$ & $14.2(12.1,16.2)$ & $7.8(6.8,8.9)$ \\
\hline
\end{tabular}

Table 4. Multilevel model results on the relationship between PA variables, perceived measure of greenness and individual characteristics.

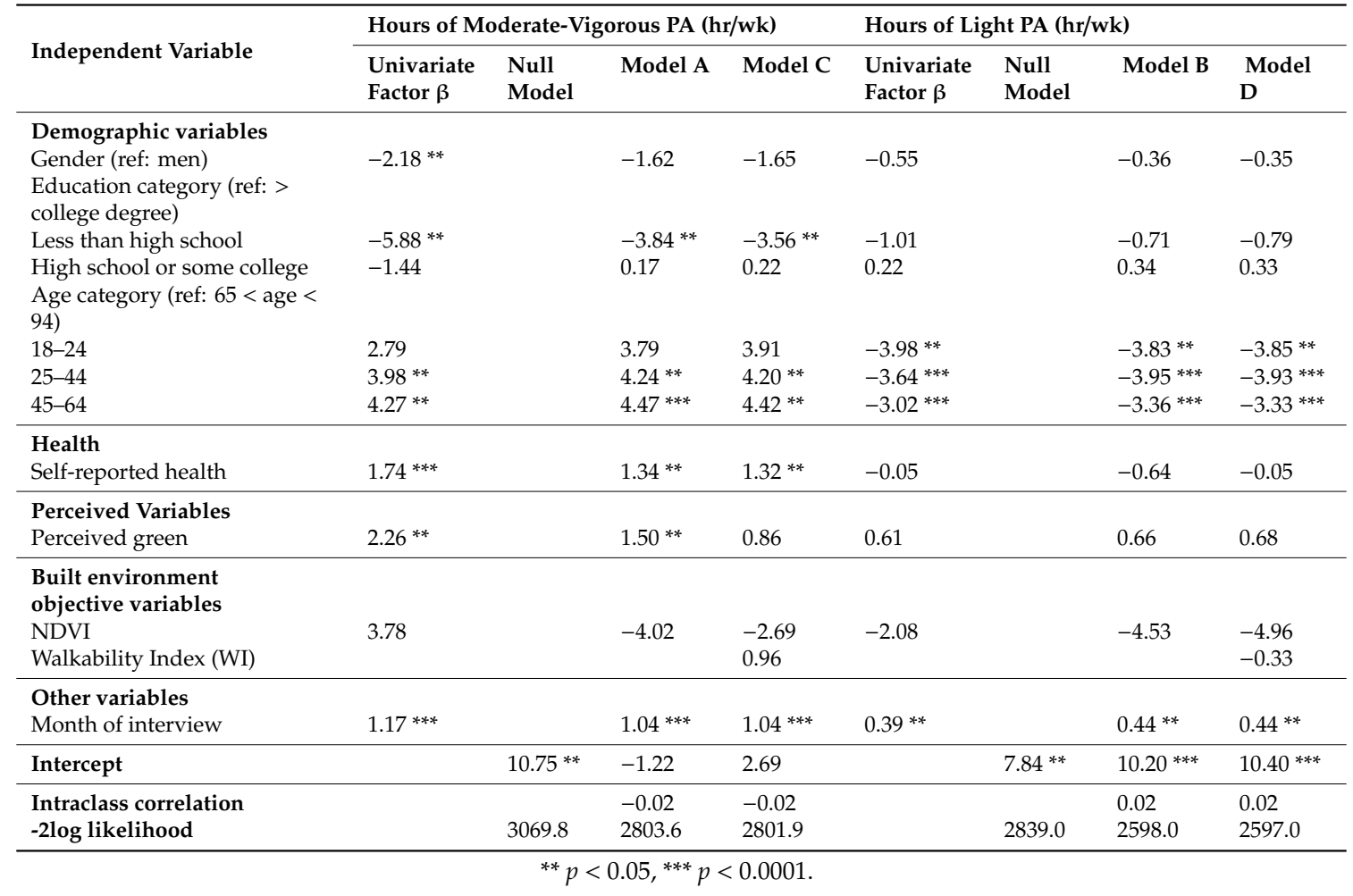


Table 5. Spearman correlations between the components of the perceived green variable.

\begin{tabular}{cccc}
\hline \multicolumn{4}{c}{ Spearman Correlation Coefficients } \\
\hline Components of Perceived Green & Trees & Shade & Presence of Nature \\
\hline Trees & 1 & $0.69^{* * *}$ & $0.48^{* * *}$ \\
\hline Shade & $0.69^{* * *}$ & 1 & $0.45^{* * *}$ \\
\hline Presence of nature & $0.48^{* * *}$ & $0.45^{* * *}$ & 1 \\
\hline & ${ }^{* * *} p<0.0001$. &
\end{tabular}

The results did not show a significant association between the two levels of PA and the objective measure of greenness, NDVI, after adjustment for demographic variables and the month of interview.

Adjusting our models for the objective level of walkability (Models C and D), coefficients of the walkability index were not statistically significant, suggesting that the relationship between PA variables and the perceived measure of greenness did not vary with the objective level of walkability.

\section{Discussion}

The present study aimed to explore the association between quality, and quantity measures of greenness and reported light and moderate-vigorous hours of PA and perceived and objective measures of greenness. It also examined whether mediator factors, such as the level of walkability affects such associations. Moreover, we aimed to investigate how quality components of greenness, trees, shade, and the presence of nature, affected the PA behavior.

Our results suggest that moderate-vigorous PA is positively influenced by the perceived greenness, which reflects people's perception of quality components of greenness in the neighborhood: trees, shade, and the presence of natural features. On the contrary, we did not observe a significant association between the quantity of greenness, represented by NDVI, and PA. Our analyses also suggest that the association between perceived greenness and PA does not vary by objective walkability levels.

\subsection{Quality of greenness and PA Behavior}

This study supported our hypothesis that there is a significant positive association between perceived greenness and PA behavior. Different mechanisms may explain this association. Quality characteristics of greenness, trees, shade and natural features provide opportunities for mental restoration and stress release [66]. Greenness advances neighborhood attachment by fostering aesthetic experience [67]. Also, street greenness is shown to be a proxy of neighborhood wealth, implying higher levels of maintenance and aesthetic qualities and lower incivilities in the neighborhood [68]. These qualities contribute to a higher perception of environmental comfort, safety and aesthetic, the three main factors that influence the desirability of the environment for PA [6,69].

The implied positive link between shade and PA in our study is consistent with findings from some studies that investigated impacts of shade in public open spaces [70]. Floyd (2008), however, links the level of walking in parks with the lower amount of shade [71]. Kegler's (2015) findings suggest that people have mixed views on whether shade influences the decisions to exercise in rural neighborhoods [72]. Generally, Camcho (2014) links people's preferences for trees and greenery to tree/greenery attributes and benefits, most importantly shade and oxygen supply [73]. Several studies suggest that the use of public spaces, such as parks, are influenced by their thermal conditions, indicating the importance of shade in outdoor environments in this regard [40,74-76].

\subsection{Quantity of Greenness and PA Behavior}

The lack of association between the quantity of greenness, measured by NDVI, and PA in this study is consistent with other studies $[19,21,77]$. The mismatch between the perceived and objective greenness measures is not surprising, as these two measures capture different aspects of neighborhood greenness. Perceived measures are usually better at capturing human aesthetic landscape values that derive from 
experiencing the environment [78], which is affected by individual factors, such as attitude, beliefs, and self-efficacy [79]. NDVI, however, is an indication of plant "greenness" or the quantity of greenery in the area. The perceived greenness, however, included people's perception of trees, shade and the presence of natural features in the neighborhood; the latter two components are not captured through NDVI. Moreover, NDVI denotes trees, as well as other vegetation, including lawns and groundcover that are both in public realms and private gardens. In reality, people are not exposed to vegetation in private yards while they are out in the neighborhood; therefore, this type of vegetation may not affect their perceptions of the desirability of neighborhood environments for PA [16,28]. Additionally, NDVI reflects the quantity of greenness and does not assess whether people have convenient access to this greenness. Some studies show that between the amount of greenness and access to greenness, the latter has a more positive effect on residents' PA behavior [80].

\subsection{Different Types of PA and Positive Perceptions of Greenness}

Our study did not support our hypothesis that positive perceptions of greenness have similar impacts on all types of PA. We found a stronger association between the reported moderate-vigorous PA and perceived greenness when compared to the association between reported light PA levels and perceived greenness. This suggests that positive perceptions of greenness many not increase the likelihood of all types of activities, but rather those activities that are undertaken outdoors in the neighborhood environment. Moderate-vigorous PA includes those activities with MET value greater than 3, such as jogging, cycling, walking fast, swimming, and so forth [61,62]. These activities are more likely to be undertaken outdoors in neighborhoods; thus, their occurrence is more likely to be influenced by people's sense of the place, and their perception of and interpretation with the surrounding environment $[6,81]$. However, light activities, such as playing instruments, dishwashing, and going to concerts are performed at home or in settings other than neighborhood streets. Thus, the intention of undertaking these "light" activities is less likely to be affected by the perception of the surrounding neighborhood.

\subsection{The Impact of Walkability}

Our findings do not detect a statistically significant difference in the relationship between PA and perceived greenness in high and low walkable neighborhoods. In that, people in both low and high walkable areas showed similar perceptions of the desirability of greenness in their neighborhood for PA. Leslie (2005), however, suggests significant differences in the perception of neighborhood environmental characteristics between residents living in objectively "high" and "low" walkable areas [52]. She found that residents in low walkable neighborhoods reported lower perceptions of residential density, land use diversity and access, connectivity, and walking infrastructure, but higher positive ratings of neighborhood aesthetics. This inconsistency between our results and those of past studies suggests that people's perception of the desirability of neighborhoods for PA does not always match the objective walkability score. Objective walkability is based on residential density, land use mix, and street connectivity; this factor does not account for design and natural features of the neighborhood that may affect people's aesthetic perceptions.

There are several limitations concerning this study. First, the CHAMPS instrument does not ask respondents where they have performed PA. In this study, we assumed that a high proportion of the reported hours of weekly activities have been carried out in the vicinity of the respondent's residence. This assumption might affect the accuracy of the results. Future studies can apply objectively measured, or geocoded PA information to examine the accuracy of our findings. Second, self-reported PA is always over-reported and is subject to social desirability and recall bias [82]. Also, the hours of moderate-vigorous-intensity PA is susceptible to be biased as CHAMPS has been shown to over-report some items, such as walking and housework [83]. Nevertheless, CHAMPS is suggested as a reliable tool to assess moderate to vigorous activities in older adults [83]. Moreover, while the magnitude of PA is over-reported, the proportional differences between social groups and across demographic variables 
are in the expected directions. Third, as a cross-sectional study, this research cannot make claims about causality between people's perception of greenness in their neighborhood and PA levels. Moreover, the degree of self-selection bias in this study is unknown and may affect the results. Furthermore, a group of our respondents was recruited from community gardens. Gardeners may have different perception of and interaction with greenness. This fact may affect the accuracy of our results. However, these gardens were located in predominantly low-income and minority areas of Denver, thus providing demographic diversity to our sample. Finally, although the survey data was collected in 2007, the data set is unique in that it allows us to study the relationships between variables of interest, drawing on objective and subjective data across a diverse sample of Denver neighborhoods and Denver residents.

\section{Conclusions}

Our findings suggest that the perception of greenness is important for influencing moderate to vigorous PA among urban residents. Relying solely on the objective measures of the built environment does not fully explain how people interact with the built environment. There are qualitative aspects of greenness, such as shade and landscape aesthetics more generally, that relate to PA. Root et al. (2017) emphasizes the importance of both perceived and objective measures. The authors suggest that the presence and quantity of the greenness by itself may not affect health behaviors, but it is the quality of the green environment and the experience with greenness that facilitates health-promoting processes and, subsequently, health status [23]. One implication is that urban planners and health officials should assess quality aspects of green space in addition to traditional, objective measures such as NDVI, tree canopy, and objective walkability indices. Also, emphasis should be placed on interventions that enhance people's perception of greenness in their neighborhood.

This research is not conclusive about the attributes of greenness, shade and trees, in particular, that affect the desirability of neighborhoods for PA. Future research studies are encouraged to examine the impact of shade and trees along with other features of streetscapes, such as sidewalks, architecture, landscapes, and maintenance on PA behavior in neighborhoods. Qualitative research methods, such as interviews, participant observation, or a visual landscape assessment survey, can help scholars and planners research the meaning of greenness for streetscapes and to evaluate factors that affect the desirability of streetscapes for PA. Understanding how shade and trees affect PA behavior will contribute to both walkability and sun safety literature.

Author Contributions: Author Contributions: S.T. and J.S.L. developed the theoretical framework and methodology for this research. S.T. performed analyses and drew results and conclusion. J.L. acquired funding for this research, developed data collection methodology, and performed data collection. A.C. provided guidance and feedback on the quantitative analysis. S.T. wrote the manuscript. All authors reviewed and edited the manuscript.

Funding: This study was supported by the Centers for Disease Control and Prevention (CDC) Health Protection Research Initiative (K01 Award EH-000066-03), the National Institutes of Health (NIH), the National Center for Research Resources (NCRR), the Colorado Clinical and Translational Sciences Institute (CCTSI) (grant UL1RR025780), Center to Advance Research and Teaching in Social Sciences (CARTSS) at the University of Colorado Boulder, and the Colorado Department of Public Health and Environment (CDPHE). The content of this manuscript is the authors' sole responsibility and does not necessarily represent the official views of the funding agencies.

Acknowledgments: This study is a result of decade-long collaborations with partners across academia, non-profits and neighborhood organizations. We would like to thank our partners in academic institutions, non-profit organizations, community gardening organizations, as well as community volunteers and students who helped with study design, data collection and data analysis. In particular we would like to acknowledge academic scholars and community investigators who helped with the completion of this work, including Brian Muller, Lori Crane, Dave Buller, Michael Buchenau, Julie Marshall, Fahriye Sancar, Joy Amulya, Mah-J Soobader, and Lisa Bardwell.

Conflicts of Interest: The authors declare no conflict of interest. The funders had no role in the design of the study; in the collection, analyses, or interpretation of data; in the writing of the manuscript, or in the decision to publish the results. 


\section{References}

1. Pate, R.R.; Pratt, M.; Blair, S.N.; Haskell, W.L.; Macera, C.A.; Bouchard, C.; Buchner, D.; Ettinger, W.; Heath, G.W.; King, A.C.; et al. Public Health and Prevention and the American College of Sports Medicine. JAMA 1995, 273.5, 402-407. [CrossRef]

2. US Department of Health and Human Services. Step it Up! The Surgeon General's Call to Action to Promote Walking and Walkable Communities; US Department of Health and Human Services: Columbia, WA, USA, 2015.

3. Laurian, L. Planning for Active Living: Should we support a new moral environmentalism? Plan. Theory Pract. 2006, 7, 117-136. [CrossRef]

4. Millstein, R.A.; Cain, K.L.; Sallis, J.F.; Conway, T.L.; Geremia, C.; Frank, L.D.; Chapman, J.; Van Dyck, D.; Dipzinski, L.R.; Kerr, J.; et al. Development, scoring, and reliability of the Microscale Audit of Pedestrian Streetscapes (MAPS). BMC Public Health 2013, 13, 403. [CrossRef] [PubMed]

5. Cole-Hunter, T.; Donaire-Gonzalez, D.; Curto, A.; Ambros, A.; Valentin, A.; Garcia-Aymerich, J.; Martínez, D.; Braun, L.M.; Mendez, M.; Jerrett, M. Objective correlates and determinants of bicycle commuting propensity in an urban environment. Transp. Res. Part D Transp. Environ. 2015, 40, 132-143. [CrossRef]

6. Mehta, V. Walkable streets: Pedestrian behavior, perceptions and attitudes. J. Urban. 2008, 1, $217-245$. [CrossRef]

7. Sugiyama, T.; Leslie, E.; Giles-Corti, B.; Owen, N. Associations of neighbourhood greenness with physical and mental health: Do walking, social coherence and local social interaction explain the relationships? J. Epidemiol. Community Health 2008, 62, e9. [CrossRef] [PubMed]

8. Sugiyama, T.; Francis, J.; Middleton, N.J.; Owen, N.; Giles-Corti, B. Associations between recreational walking and attractiveness, size, and proximity of neighborhood open spaces. Am. J. Public Health 2010, 100, 1752-1757. [CrossRef] [PubMed]

9. Pereira, G.; Christian, H.; Foster, S.; Boruff, B.J.; Bull, F.; Knuiman, M.; Giles-Corti, B. The association between neighborhood greenness and weight status: An observational study in Perth Western Australia. Environ. Health 2013, 12, 49. [CrossRef]

10. De Vries, S.; van Dillen, S.M.E.; Groenewegen, P.P.; Spreeuwenberg, P. Streetscape greenery and health: Stress, social cohesion and physical activity as mediators. Soc. Sci. Med. 2013, 94, 26-33. [CrossRef]

11. Maller, C.; Townsend, M.; Pryor, A.; Brown, P.; St Leger, L. Healthy nature healthy people: “Contact with nature" as an upstream health promotion intervention for populations. Health Promot. Int. 2006, 21, 45-54. [CrossRef]

12. Ward Thompson, C.; Aspinall, P.A. Natural environments and their impact on activity, health, and quality of life. Appl. Psychol. Heal. Well-Being 2011, 3, 230-260. [CrossRef]

13. Ward Thompson, C. Linking landscape and health: The recurring theme. Landsc. Urban Plan. 2011, 99, 187-195. [CrossRef]

14. Litt, J.S.; Schmiege, S.; Hale, J.W.; Buchenau, M.; Sancar, F. Exploring ecological, emotional and social levers of self-rated health for urban gardeners and non-gardeners: A path analysis. Soc. Sci. Med. 2015, 144, 1-8. [CrossRef] [PubMed]

15. Calogiuri, G.; Chroni, S. The impact of the natural environment on the promotion of active living: An integrative systematic review. BMC Public Health 2010. [CrossRef] [PubMed]

16. Sarkar, C.; Webster, C.; Pryor, M.; Tang, D.; Melbourne, S.; Zhang, X.; Jianzheng, L. Exploring associations between urban green, street design and walking: Results from the Greater London boroughs. Landsc. Urban Plan. 2015, 143, 112-125. [CrossRef]

17. Coombes, E.; Jones, A.P.; Hillsdon, M. Social Science \& Medicine The relationship of physical activity and overweight to objectively measured green space accessibility and use q. Soc. Sci. Med. 2010, 70, 816-822. [CrossRef] [PubMed]

18. Foster, C.; Hillsdon, M.; Jones, A.; Grundy, C.; Wilkinson, P.; White, M.; Sheehan, B.; Wareham, N.; Thorogood, M. Objective Measures of the Environment and Physical Activity-Results of the Environment and Physical Activity Study in English Adults. J. Phys. Act. Health 2009, 6, 70-81. [CrossRef]

19. Hillsdon, M.; Panter, J.; Foster, C.; Jones, A. The relationship between access and quality of urban green space with population physical activity. Public Health 2006, 120, 1127-1132. [CrossRef] [PubMed]

20. Duncan, M.; Mummery, K. Psychosocial and environmental factors associated with physical activity among city dwellers in regional Queensland. Prev. Med. 2005, 40, 363-372. [CrossRef] [PubMed] 
21. Prince, S.A.; Kristjansson, E.A.; Russell, K.; Billette, J.; Sawada, M.; Ali, A.; Tremblay, M.S.; Prud, D. A Multilevel Analysis of Neighbourhood Built and Social Environments and Adult Self-Reported Physical Activity and Body Mass Index in Ottawa, Canada. Int. J. Environ. Res. Public Health 2011, 8, 3953-3978. [CrossRef]

22. Gobster, P.H.; Nassauer, J.I.; Daniel, T.C.; Fry, G. The shared landscape: What does aesthetics have to do with ecology? Landsc. Ecol. 2007, 22, 959-972. [CrossRef]

23. Root, E.D.; Silbernagel, K.; Litt, J.S. Unpacking healthy landscapes: Empirical assessment of neighborhood aesthetic ratings in an urban setting. Landsc. Urban Plan. 2017, 168, 38-47. [CrossRef]

24. Daniel, T.C. Whither scenic beauty? Visual landscape quality assessment in the 21st century. Landsc. Urban Plan. 2001, 54, 267-281. [CrossRef]

25. Pikora, T.; Giles-Corti, B.; Bull, F.; Jamrozik, K.; Donovan, R. Developing a framework for assessment of the environmental determinants of walking and cycling. Soc. Sci. Med. 2003, 56, 1693-1703. [CrossRef]

26. Ball, K.; Bauman, A.; Leslie, E.; Owen, N. Perceived Environmental Aesthetics and Convenience and Company Are Associated with Walking for Exercise among Australian Adults. Prev. Med. 2001, 33, 434-440. [CrossRef] [PubMed]

27. Handy, S.L.; Boarnet, M.G.; Ewing, R.; Killingsworth, R.E. How the built environment affects physical activity: Views from urban planning. Am. J. Prev. Med. 2002, 23, 64-73. [CrossRef]

28. Leslie, E.; Sugiyama, T.; Lerodiaconou, D.; Kremer, P. Perceived and objectively measured greenness of neighbourhoods: Are they measuring the same thing? Landsc. Urban Plan. 2010, 95, 28-33. [CrossRef]

29. Saelens, B.E.; Sallis, J.F.; Black, J.B.; Chen, D. Neighborhood-Based Differences in Physical Activity: An Environment Scale Evaluation. Am. J. Public Health 2003, 93, 1552-1558. [CrossRef] [PubMed]

30. Owen, N.; Humpel, N.; Leslie, E.; Bauman, A.; Sallis, J.F. Review and Research Agenda. Am. J. Prev. Med. 2004, 27, 67-76. [CrossRef] [PubMed]

31. Gladwell, V.F.; Brown, D.K.; Wood, C.; Sandercock, G.R.; Barton, J.L. The great outdoors: How a green exercise environment can benefit all. Extrem. Physiol. Med. 2013, 2, 3. [CrossRef] [PubMed]

32. Nasar, J.L.; Holloman, C.; Abdulkarim, D. Street characteristics to encourage children to walk. Transp. Res. Part A Policy Pract. 2015, 72, 62-70. [CrossRef]

33. Van den Berg, M.; Wendel-Vos, W.; Van Poppel, M.; Kemper, H.; Van Mechelen, W.; Maas, J. Health benefits of green spaces in the living environment: A systematic review of epidemiological studies. Urban For. Urban Green. 2015, 14, 806-816. [CrossRef]

34. Boldemann, C.; Blennow, M.; Dal, H.; Mårtensson, F.; Raustorp, A.; Yuen, K.; Wester, U. Impact of preschool environment upon children's physical activity and sun exposure. Prev. Med. 2006, 42, 301-308. [CrossRef] [PubMed]

35. Cohen, D.A.; Ashwood, J.S.; Scott, M.M.; Overton, A.; Evenson, K.R.; Staten, L.K.; Porter, D.; McKenzie, T.L.; Catellier, D. Public parks and physical activity among adolescent girls. Pediatrics 2006, 118, e1381-e1389. [CrossRef] [PubMed]

36. Ferré, M.B.; Guitart, A.O.; Ferret, M.P. Children and playgrounds in Mediterranean cities. Child. Geogr. 2006, 4, 173-183. [CrossRef]

37. Timperio, A.; Giles-Corti, B.; Crawford, D.; Andrianopoulos, N.; Ball, K.; Salmon, J.; Hume, C. Features of public open spaces and physical activity among children: Findings from the CLAN study. Prev. Med. 2008, 47, 514-518. [CrossRef] [PubMed]

38. Tucker, P.; Gilliland, J.; Irwin, J.D. Splashpads, swings, and shade: parents' preferences for neighbourhood parks. Can. J. Public Health 2007, 98, 198-202. [CrossRef] [PubMed]

39. Veitch, J.; Bagley, S.; Ball, K.; Salmon, J. Where do children usually play? A qualitative study of parents' perceptions of influences on children's active free-play. Health Place 2006, 12, 383-393. [CrossRef] [PubMed]

40. Li, X.; Ratti, C.; Seiferling, I. Quantifying the shade provision of street trees in urban landscape: A case study in Boston, USA, using Google Street View. Landsc. Urban Plan. 2018, 169, 81-91. [CrossRef]

41. Cao, X.; Handy, S.L.; Mokhtarian, P.L. The influences of the built environment and residential self-selection on pedestrian behavior: Evidence from Austin, TX. Transportation 2006, 33, 1-20. [CrossRef]

42. Handy, S.L.; Clifton, K.; Fisher, J. The Effectiveness of Land Use Policies as a Strategy for Reducing Automobile Dependence: A Study of Austin Neighborhoods; Southwest Region University Transportation Center, Center for Transportation Research, University of Texas at Austin: Austin, TX, USA, 1998. 
43. Ramirez, L.K.B.; Hoehner, C.M.; Brownson, R.C.; Cook, R.; Orleans, C.T.; Hollander, M.; Barker, D.C.; Bors, P.; Ewing, R.; Killingsworth, R. Indicators of activity-friendly communities: An evidence-based consensus process. Am. J. Prev. Med. 2006, 31, 515-524.

44. Schipperijn, J.; Ekholm, O.; Stigsdotter, U.K.; Toftager, M.; Bentsen, P.; Kamper-Jørgensen, F.; Randrup, T.B. Factors influencing the use of green space: Results from a Danish national representative survey. Landsc. Urban Plan. 2010, 95, 130-137. [CrossRef]

45. Maas, J.; Verheij, R.A.; Spreeuwenberg, P.; Groenewegen, P.P. Physical activity as a possible mechanism behind the relationship between green space and health: A multilevel analysis. BMC Public Health 2008, 8, 206. [CrossRef] [PubMed]

46. Kaczynski, A.T.; Potwarka, L.R.; Smale, B.J.A.; Havitz, M.E. Association of parkland proximity with neighborhood and park-based physical activity: Variations by gender and age. Leis. Sci. 2009, 31, 174-191. [CrossRef]

47. Sallis, J.F.; Cervero, R.B.; Ascher, W.; Henderson, K.A.; Kraft, M.K.; Kerr, J. An ecological approach to creating active living communities. Annu. Rev. Public Health 2006, 27, 297-322. [CrossRef] [PubMed]

48. Carver, A.; Timperio, A.; Crawford, D. Playing it safe: The influence of neighbourhood safety on children's physical activity-A review. Health Place 2008, 14, 217-227. [CrossRef] [PubMed]

49. Carver, A.; Salmon, J.; Campbell, K.; Baur, L.; Garnett, S.; Crawford, D. How do perceptions of local neighborhood relate to adolescents' walking and cycling? Am. J. Health Promot. 2005, 20, 139-147. [CrossRef]

50. Weir, L.A.; Etelson, D.; Brand, D.A. Parents' perceptions of neighborhood safety and children's physical activity. Prev. Med. 2006, 43, 212-217. [CrossRef]

51. Gomez, J.E.; Johnson, B.A.; Selva, M.; Sallis, J.F. Violent crime and outdoor physical activity among inner-city youth. Prev. Med. 2004, 39, 876-881. [CrossRef]

52. Leslie, E.; Saelens, B.; Frank, L.; Owen, N.; Bauman, A.; Coffee, N.; Hugo, G. Residents' perceptions of walkability attributes in objectively different neighbourhoods: A pilot study. Health Place 2005, 11, 227-236. [CrossRef]

53. Bonnes, M.; Bonaiuto, M.; Aiello, A.; Perugini, M.; Ecolani, A.P. A Transactional Perspective on Residential Satisfaction; CRAD: Quebec City, QC, Canada, 1997.

54. Brown, B.; Perkins, D.D.; Brown, G. Place attachment in a revitalizing neighborhood: Individual and block levels of analysis. J. Environ. Psychol. 2003, 23, 259-271. [CrossRef]

55. Comstock, N.; Miriam Dickinson, L.; Marshall, J.A.; Soobader, M.J.; Turbin, M.S.; Buchenau, M.; Litt, J.S. Neighborhood attachment and its correlates: Exploring neighborhood conditions, collective efficacy, and gardening. J. Environ. Psychol. 2010, 30, 435-442. [CrossRef]

56. Litt, J.S.; Soobader, M.-J.; Turbin, M.S.; Hale, J.W.; Buchenau, M.; Marshall, J.A. The influence of social involvement, neighborhood aesthetics, and community garden participation on fruit and vegetable consumption. Am. J. Public Health 2011, 101, 1466-1473. [CrossRef] [PubMed]

57. Theall, K.P.; Scribner, R.; Broyles, S.; Yu, Q.; Chotalia, J.; Simonsen, N.; Schonlau, M.; Carlin, B.P. Impact of small group size on neighbourhood influences in multilevel models. J. Epidemiol. Community Health 2011, 65, 688-695. [CrossRef] [PubMed]

58. Clarke, P. When can group level clustering be ignored? Multilevel models versus single-level models with sparse data. J. Epidemiol. Community Health 2008, 62, 752-758. [CrossRef] [PubMed]

59. Sampson, R.J.; Raudenbush, S.W.; Earls, F. Neighborhoods and violent crime: A multilevel study of collective efficacy. Science 1997, 277, 918-924. [CrossRef]

60. Bonaiuto, M.; Aiello, A.; Perugini, M.; Bonnes, M.; Ercolani, A.P. Multidimensional perception of residential environment quality and neighbourhood attachment in the urban environment. J. Environ. Psychol. 1999, 19, 331-352. [CrossRef]

61. Stewart, A.L.; Mills, K.M.; King, A.C.; Haskell, W.L.; Gillis, D.; Ritter, P.L. CHAMPS physical activity questionnaire for older adults: Outcomes for interventions. Med. Sci. Sports Exerc. 2001, 33, 1126-1141. [CrossRef]

62. Centers for Disease Control and Prevention General Physical Activities Defined by Level of Intensity. Available online: https://www.cdc.gov/nccdphp/dnpa/physical/pdf/PA_Intensity_table_2_1.pdf (accessed on 15 March 2018).

63. Centers for Disease Control and Prevention. Behavioral Risk Factor Surveillance System Survey Questionnaire; Centers for Disease Control and Prevention: Atlanta, GA, USA, 2007. 
64. Frank, L.D.; Sallis, J.F.; Saelens, B.E.; Leary, L.; Cain, K.; Conway, T.L.; Hess, P.M. The development of a walkability index: Application to the Neighborhood Quality of Life Study. Br. J. Sports Med. 2010, 44, 924-933. [CrossRef]

65. Manaugh, K.; Kreider, T. What is mixed use? Presenting an interaction method for measuring land use mix. J. Transp. Land Use 2013, 6, 63-72. [CrossRef]

66. Maas, J.; van Dillen, S.M.E.; Verheij, R.A.; Groenewegen, P.P. Social contacts as a possible mechanism behind the relation between green space and health. Health Place 2009, 15, 586-595. [CrossRef]

67. Arnberger, A.; Eder, R. The influence of green space on community attachment of urban and suburban residents. Urban For. Urban Green. 2012, 11, 41-49. [CrossRef]

68. Anderson, L.M.; Cordell, H.K. Influence of trees on residential property values in Athens, Georgia (USA): A survey based on actual sales prices. Landsc. Urban Plan. 1988, 15, 153-164. [CrossRef]

69. Alfonzo, M.A. To walk or not to walk? The hierarchy of walking needs. Environ. Behav. 2005, 37, 808-836. [CrossRef]

70. Giles-Corti, B.; Broomhall, M.H.; Knuiman, M.; Collins, C.; Douglas, K.; Ng, K.; Lange, A.; Donovan, R.J. Increasing walking: How important is distance to, attractiveness, and size of public open space? Am. J. Prev. Med. 2005, 28, 169-176. [CrossRef]

71. Floyd, M.F.; Spengler, J.O.; Maddock, J.E.; Gobster, P.H.; Suau, L. Environmental and social correlates of physical activity in neighborhood parks: An observational study in Tampa and Chicago. Leis. Sci. 2008, 30, 360-375. [CrossRef]

72. Kegler, M.C.; Alcantara, I.; Haardörfer, R.; Gemma, A.; Ballard, D.; Gazmararian, J. Rural neighborhood walkability: Implications for assessment. J. Phys. Act. Health 2015, 12, S40-S45. [CrossRef]

73. Camacho-Cervantes, M.; Schondube, J.E.; Castillo, A.; MacGregor-Fors, I. How do people perceive urban trees? Assessing likes and dislikes in relation to the trees of a city. Urban Ecosyst. 2014, 17, 761-773. [CrossRef]

74. Thorsson, S.; Honjo, T.; Lindberg, F.; Eliasson, I.; Lim, E.-M. Thermal comfort and outdoor activity in Japanese urban public places. Environ. Behav. 2007, 39, 660-684. [CrossRef]

75. Chen, L.; $\mathrm{Ng}$, E. Outdoor thermal comfort and outdoor activities: A review of research in the past decade. Cities 2012, 29, 118-125. [CrossRef]

76. Lin, C.-H.; Lin, T.-P.; Hwang, R.-L. Thermal comfort for urban parks in subtropics: Understanding visitor's perceptions, behavior and attendance. Adv. Meteorol. 2013, 2013. [CrossRef]

77. Tilt, J.H.; Unfried, T.M.; Roca, B. Using objective and subjective measures of neighborhood greenness and accessible destinations for understanding walking trips and BMI in Seattle, Washington. Am. J. Health Promot. 2007, 21, 371-379. [CrossRef] [PubMed]

78. Jorgensen, A.; Gobster, P.H. Shades of green: Measuring the ecology of urban green space in the context of human health and well-being. Nat. Cult. 2010, 5, 338-363. [CrossRef]

79. Jack, E.; McCormack, G.R. The associations between objectively-determined and self-reported urban form characteristics and neighborhood-based walking in adults. Int. J. Behav. Nutr. Phys. Activity 2014, 11, 71. [CrossRef] [PubMed]

80. Wilson, L.-A.M.; Giles-Corti, B.; Burton, N.W.; Giskes, K.; Haynes, M.; Turrell, G. The association between objectively measured neighborhood features and walking in middle-aged adults. Am. J. Heal. Promot. 2011, 25, e12-e21. [CrossRef] [PubMed]

81. Blacksher, E.; Lovasi, G.S. Place-focused physical activity research, human agency, and social justice in public health: Taking agency seriously in studies of the built environment. Health Place 2012, 18, 172-179. [CrossRef] [PubMed]

82. Adams, S.A.; Matthews, C.E.; Ebbeling, C.B.; Moore, C.G.; Cunningham, J.E.; Fulton, J.; Hebert, J.R. The effect of social desirability and social approval on self-reports of physical activity. Am. J. Epidemiol. 2005, 161, 389-398. [CrossRef] [PubMed]

83. Hekler, E.B.; Buman, M.P.; Haskell, W.L.; Conway, T.L.; Cain, K.L.; Sallis, J.F.; Saelens, B.E.; Frank, L.D.; Kerr, J.; King, A.C. Reliability and validity of CHAMPS self-reported sedentary-to-vigorous intensity physical activity in older adults. J. Phys. Act. Health 2012, 9, 225-236. [CrossRef]

(C) 2019 by the authors. Licensee MDPI, Basel, Switzerland. This article is an open access article distributed under the terms and conditions of the Creative Commons Attribution (CC BY) license (http://creativecommons.org/licenses/by/4.0/). 